\title{
Temperature effects in barium sorption on natural kaolinite and chlorite-illite clays
}

\author{
T. Shahwan, H. N. Erten* \\ Department of Chemistry, Bilkent University, 06800 Bilkent, Ankara, Turkey
}

(Received May 10, 2003)

The sorption of $\mathrm{Ba}^{2+}$ ion on natural kaolinite and chlorite-illite clays was investigated at different initial concentrations and temperatures using the

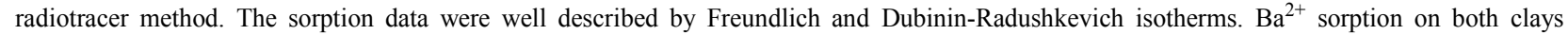
showed an exothermic behavior with $\Delta H^{\circ}(\mathrm{kJ} / \mathrm{mol})$ values being -7 and -5 for sorption on kaolinite and chlorite illite mixed clay, respectively. The $\Delta G^{\circ}$ values indicate that the sorption was spontaneous with sorption energies corresponding to ion-exchange type sorption. X-ray diffraction studies showed that no significant change in the matrix of the clays occurred upon $\mathrm{Ba}^{2+}$ sorption.

\section{Introduction}

Geological disposal is considered as one of the most promising solutions that ensures a safe storage of radioactive wastes. Kaolinite, chlorite, and illite are examples of clay minerals that are widely available across the world. These clays are referred to as aluminosilicates, the structures of which are composed of aluminum octahedron and silicon tetrahedron sheets. The way those sheets are stacked to form layers and the nature of connecting forces among the layers largely determine the type of the clay. Different structural features are reflected in varying sorption properties. The wide availability, thermal stability, and strong sorption characteristics of clay minerals makes them good candidates as backfill materials in the radioactive waste repositories.

Barium is an alkaline earth element $(Z=56)$, its radioactive isotope ${ }^{140} \mathrm{Ba}\left(T_{1 / 2}=12.79 \mathrm{~d}\right)$ is a fission product with a high yield $(6.21 \%) .{ }^{1}$ This radionuclide is a serious radiocontaminant, furthermore being a homologue of $\mathrm{Ra}, \mathrm{Ba}^{2+}$ is a suitable cation for the radiochemical study of $\mathrm{Ra}^{2+}$, which have several radioisotopes that are important in radioactive waste considerations. ${ }^{133} \mathrm{Ba}^{2+}$ was chosen as a radiotracer in our studies because of its long half-life $\left(T_{1 / 2}=10.7 \mathrm{y}\right)$ and a $\gamma$-ray at $356 \mathrm{keV}$ energy.

The effects of various parameters on the sorption behavior of $\mathrm{Ba}^{2+}$ on clays were reported earlier by different studies. ${ }^{2-10}$ In this work, the sorption behavior of $\mathrm{Ba}^{2+}$ on kaolinite and chlorite-illite mixed clay as a function of temperature, contact time and initial $\mathrm{Ba}^{2+}$ ion concentration was studied. Incorporating temperature effects in the studies led to the determination of enthalpy, entropy and free energy of sorption. The results are reported for the first time. The nature of $\mathrm{Ba}^{2+}$ uptake on various clay lattices was also studied using X-ray diffraction (XRD) techniques.

\section{Experimental}

The natural clay mineral samples were obtained from the Turkish General Directorate of Mineral Research and Exploration (MTA). The clay minerals originated from Sindirgi and Afyon regions of Turkey. Both Sindirgi and Afyon are located in the western part of Anatolia. The X-ray powder diffraction (XRD) diagrams were collected on a Rigaku Miniflex diffractometer using a high powder $\mathrm{Cu}-\mathrm{K} \alpha$ source operating at $30 \mathrm{kV}$ and $15 \mathrm{~mA}$. The measurements were recorded in the $2 \theta$ range of $2-30$ at $2.0 \theta / \mathrm{min}$ scan rate and 0.01 step intervals. According to the XRD analysis, Sindirgi clay was composed of kaolinite and some quartz, and Afyon clay contained primarily chlorite and illite together with some calcite and quartz. The XRD patterns of the clays prior to sorption are shown in Figs 1a and 2a.

The particle size of the natural clay samples obtained by dry and wet seeving techniques and used in the experiments were all $<38 \mu \mathrm{m}$. The batch method was used throughout the study. Prior to the sorption experiments, pretreatment of the clay samples was carried out aiming to mimic the equilibrium between the clay samples and groundwater. Aliquots of $30 \mathrm{mg}$ of the clay were introduced into pre-weighed tubes, and $3 \mathrm{ml}$ of laboratory tap-water, having similar composition to groundwater, were added into each tube which were then shaken for two days with a lateral shaker at $125 \mathrm{rpm}$. Samples were then centrifuged at $6000 \mathrm{rpm}$ for 30 minutes and the liquid phases were discarded. Each tube was then weighed to determine the small amount of water remaining $\left(\Delta W_{\mathrm{pt}}\right)$. The cation composition of Bilkent tap-water was determined by flame atomic absorption spectroscopy (FAAS). The average concentrations (mol/L) of $\mathrm{Na}^{+}, \mathrm{K}^{+}, \mathrm{Mg}^{2+}$, and $\mathrm{Ca}^{2+}$ in Bilkent tap-water before sorption were $3.92 \cdot 10^{-4}$, $1.04 \cdot 10^{-4}, 2.15 \cdot 10^{-4}$, and $1.62 \cdot 10^{-4}$, respectively. 


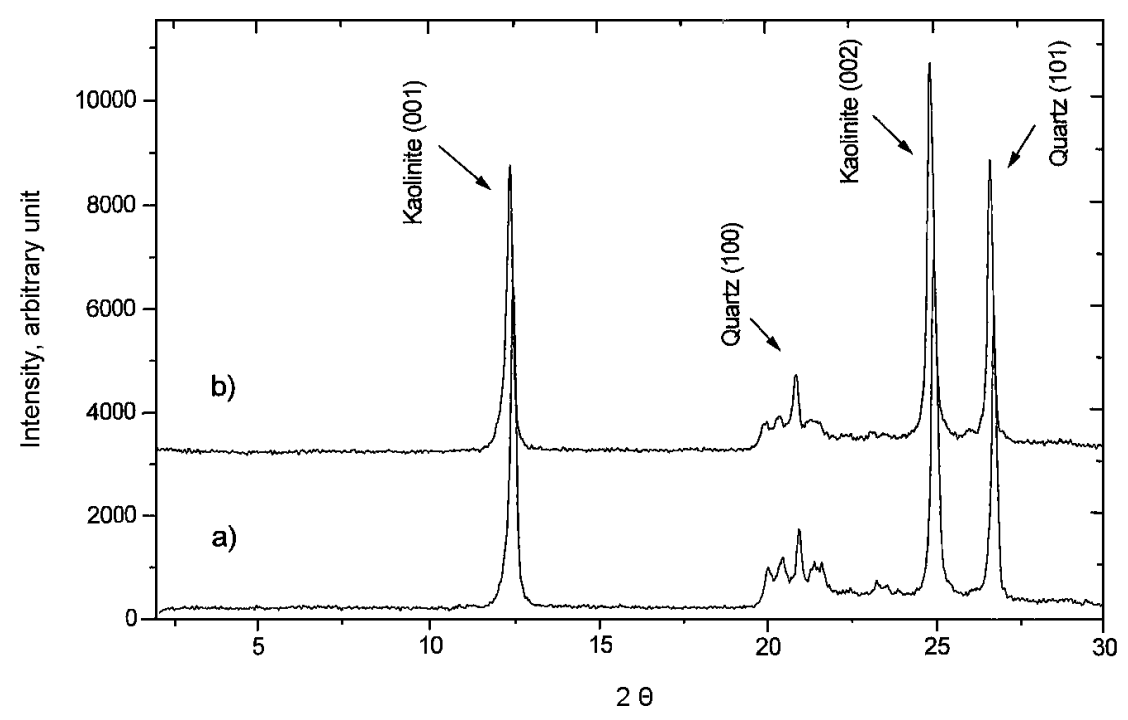

Fig. 1. XRD diagrams of natural kaolinite (a), and Ba-sorbed kaolinite (b)

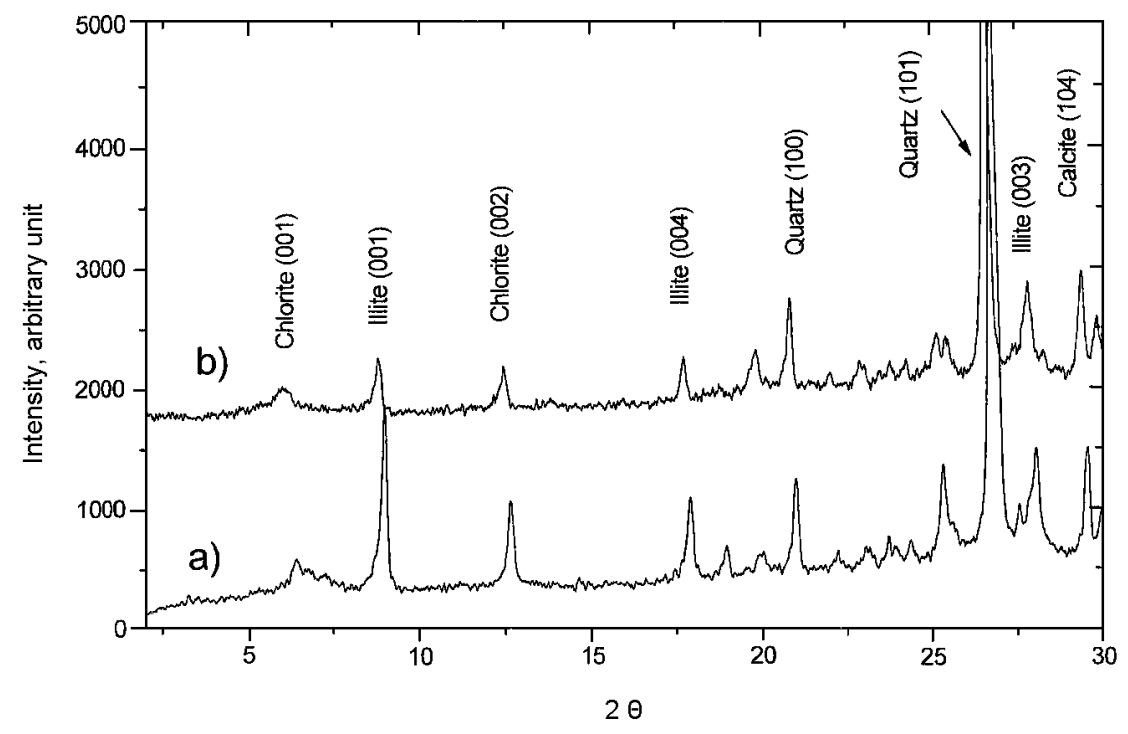

Fig. 2. XRD diagrams of natural chlorite-illite (a), and Ba-sorbed chlorite-illite (b)

To each of the $30 \mathrm{mg}$ pretreated clay samples, $3 \mathrm{ml}$ of $\mathrm{Ba}^{2+}$ solutions spiked with ${ }^{133} \mathrm{Ba}$ radiotracer was added. A typical initial count rate was measured as $19136 \pm 138 \mathrm{cpm}$ for a $3 \mathrm{ml}$ aliquot. In the kinetic experiments the initial concentration of $\mathrm{Ba}^{2+}$ ions was $5 \cdot 10^{-4} \mathrm{~mol} / 1$ and tubes were shaken at room temperature $\left(25^{\circ} \mathrm{C}\right)$ for periods ranging from one hour to seven days. The loading experiments were performed at $\mathrm{Ba}^{2+}$ ion initial concentrations of $5 \cdot 10^{-4}, 5 \cdot 10^{-5}, 5 \cdot 10^{-6}$ and $5 \cdot 10^{-7} \mathrm{~mol} / \mathrm{l}$ at four different temperatures; $30,40,50$ and $60{ }^{\circ} \mathrm{C}$. Based on the results of the kinetic experiments, the samples were shaken for two days in these experiments. Shaking was done in a temperaturecontrolled environment using a water bath shaker equipped with a microprocessor thermostat. Following shaking, tubes were centrifuged and $2 \mathrm{ml}$ portions of the supernatant were counted using a $35 \mathrm{~cm}^{3}$ HPGe detector connected to a multichannel analyzer. Duplicate sets of experiments were conducted in parallel.

Tubes were vigorously shaken prior to centrifugation to collect any liquid drops or clay particles adhering to the inside surface of each tube. The uncertainties in the measurements stemmed primarly from those of counting statistics. Other error sources of less importance were those originating from weight and volume measurements. The overall standard uncertainty in the $R_{d}$ values was estimated from Eq. (1) to be less than $\pm 10 \%$ in all cases. 


\section{Results and discussion}

The experimental data were expressed in terms of the distribution ratio, $R_{d}$, given as:

$$
R_{d}=\frac{V A^{\circ}-\left(V+\Delta W_{p t}\right) A_{1}}{A_{1} W_{s}}
$$

where $R_{d}$ is the distribution ratio $(\mathrm{ml} / \mathrm{g}), A^{\circ}$ is the initial count rate of solution added for sorption $(\mathrm{cps} / \mathrm{ml}), A_{1}$ is the count rate of solution after sorption $(\mathrm{cps} / \mathrm{ml}), V$ is the volume of solution $(\mathrm{ml}), W_{s}$ is the weight of solid material $(\mathrm{g})$ and $\Delta W_{p t}$ is the amount of liquid remaining in the tube after pretreatment, before sorption $(\mathrm{g})$.

The variations of the $R_{d}$ values for $\mathrm{Ba}^{2+}$ sorption on kaolinite and chlorite-illite as a function of time indicate a fast sorption process where equilibrium is approached within about two days of contact. Such a period indicates that sorption is primarily a surface phenomena where the clay surface is readily accessible to ions in solution. On this basis, a sorption time of 2 days was chosen as a fixed parameter in further experiments investigating the effects of loading and temperature on sorption.

\section{The loading curves}

The loading experiments investigated the effect of initial cation concentration on sorption at various temperatures. $R_{d}$ values of $\mathrm{Ba}^{2+}$ sorption on the clays at various initial concentrations and temperatures are given in Table 1. It is observed that for each temperature the $R_{d}$ values decrease as the initial $\mathrm{Ba}^{2+}$ concentration is increased. This stems from the fact that as the initial concentration of the sorbed cation increases, the ratio of the ions that are accommodated by the solid surface to those remaining in solution decreases since a limited number of sites on the clay are available for sorption. Higher $R_{d}$ values were obtained for sorption on chloriteillite compared to kaolinite indicating more accessible sorption sites in the former case. It is observed that the $R_{d}$ values corresponding to sorption on chlorite-illite decrease significantly as the initial $\mathrm{Ba}^{2+}$ concentration is increased to $5 \cdot 10^{-4} \mathrm{~mol} / \mathrm{l}$. This might be indicative that less favorable sorption sites becomes involved as the concentration increases, or that saturation is approached.

The loading curves were constructed by plotting $R_{d}$ values against $\log [C]_{S}$, as illustrated in Fig. 3 for $\mathrm{Ba}^{2+}$ sorption on kaolinite and chlorite-illite at various temperatures. The loading curves of kaolinite indicate that a single sorption site is involved in sorption. Kaolinite layers are tightly bound via hydrogen bonding and as a result, surface sorption is prominent while interlayer sorption is difficult. The chlorite-illite curves imply that at least two sorption sites exist. Thus sorption takes place on different sites with varying sorption energies. Sorption of $\mathrm{Ba}^{2+}$ on both kaolinite and chlorite-illite clays approaches saturation at higher loadings.

\section{Freundlich isotherms}

Freundlich isotherm model is the most widely used non-linear model for describing the dependence of sorption on sorbate concentration. This model allows for several kinds of sorption sites on the solid and represents properly the sorption data at low and intermediate concentrations on heterogeneous surfaces. The general expression of Freundlich isotherm is given as:

$$
[C]_{S}=k[C]_{l}^{n}
$$

where $[C]_{S}$ is the amount of ionic species adsorbed on the solid matrix at equilibrium $(\mathrm{mol} / \mathrm{kg}),[C]_{l}$ is the concentration of the cation in solution at equilibrium (mol/l), $k$ and $n$ are Freundlich constants.

This expression can be linearized as:

$$
\log [C]_{S}=\log k+n \log [C]_{l}
$$

Plotting $\log [C]_{S}$ versus $\log [C]_{l}$ yields $n$ as the slope and $\log k$ as the intercept. The results of Freundlich isotherm fits to the data of $\mathrm{Ba}^{2+}$ sorption on kaolinite and chlorite-illite are given in Table 2.

Table 1. Variation of $R_{d}$ (in $\mathrm{ml} / \mathrm{g}$ ) as a function of loading and temperature for $\mathrm{Ba}^{2+}$ sorption on kaolinite and chlorite-illite

\begin{tabular}{lccccc}
\hline Clay & $C^{\circ}, \mathrm{mol} / \mathrm{l}$ & $303 \mathrm{~K}$ & $313 \mathrm{~K}$ & $323 \mathrm{~K}$ & $333 \mathrm{~K}$ \\
\hline Kaolinite & $5 \cdot 10^{-7}$ & 340 & 310 & 300 & 280 \\
& $5 \cdot 10^{-6}$ & 270 & 260 & 270 & 254 \\
& $5 \cdot 10^{-5}$ & 180 & 160 & 160 & 130 \\
Chlorite-illite & $5 \cdot 10^{-4}$ & 44 & 42 & 33 & 33 \\
& $5 \cdot 10^{-7}$ & 1270 & 1200 & 1050 & 960 \\
& $5 \cdot 10^{-6}$ & 870 & 780 & 740 & 730 \\
& $5 \cdot 10^{-5}$ & 740 & 690 & 710 & 630 \\
& $5 \cdot 10^{-4}$ & 170 & 170 & 170 & 170 \\
\hline
\end{tabular}



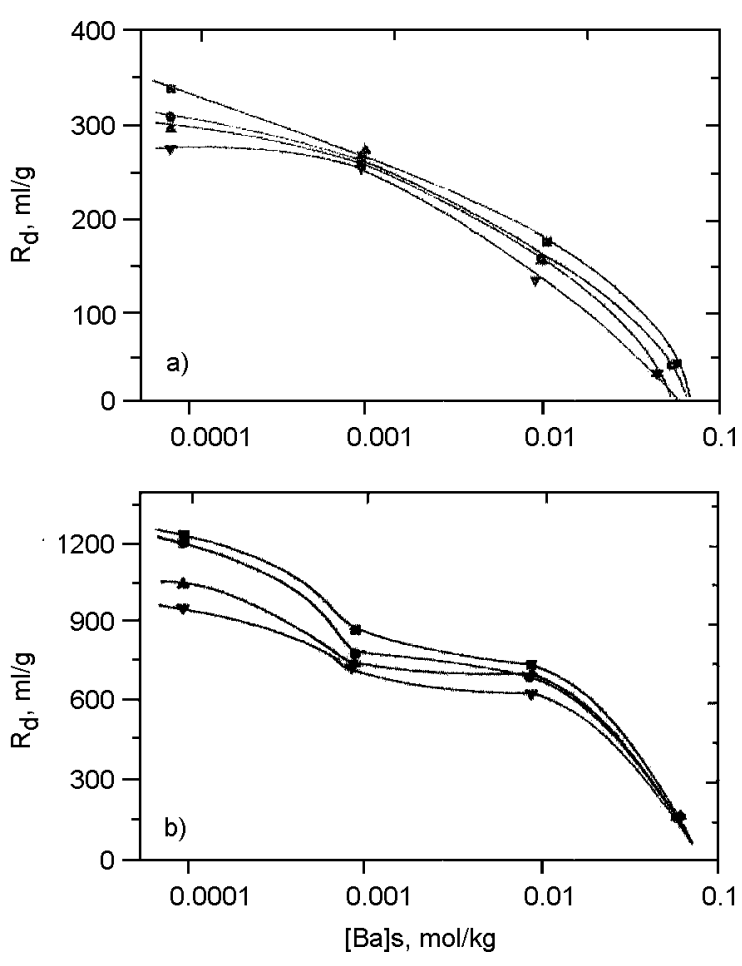

Fig. 3. Loading curves of $\mathrm{Ba}^{2+}$ sorption on: kaolinite (a), chlorite-illite (b) at different temperatures: $\square 30{ }^{\circ} \mathrm{C} ; \bullet 40{ }^{\circ} \mathrm{C} ; \boldsymbol{\Delta} 50{ }^{\circ} \mathrm{C} ; \boldsymbol{\nabla} 60{ }^{\circ} \mathrm{C}$

The constant $k$ provides information about the relative sorption affinity of the clay towards the sorbed cation and the magnitude of constant $n$ is an indicator of the deviation of sorption from linearity. Non-linear sorption takes place on heterogeneous surfaces. This behavior implies that the sorption energy barrier increases exponentially as the fraction of filled sites on the clay increases, hence an increase in the initial concentration leads to a decrease in the $R_{d}$ values. The magnitudes of $k$ values given in Table 2 indicate that chlorite-illite has a higher sorption affinity towards $\mathrm{Ba}^{2+}$ ions. Increase of temperature has no pronounced effect on $n$ values for both clays, but unlike chlorite-illite the $k$ values corresponding to kaolinite somewhat decrease with increasing temperature.

\section{Dubinin-Radushkevich (D-R) isotherm}

The D-R isotherm model is valid at low concentration ranges and can be used to describe sorption on both homogeneous and heterogeneous surfaces. It can be represented by the general expression:

$$
[C]_{S}=C_{m} \exp -\left(K \varepsilon^{2}\right)
$$

where $[C]_{S}$ and $[C]_{l}$ are as defined above, $\varepsilon$ is the Polanyi potential, given as $R T \ln \left(1+1 /[C]_{l}\right), R$ is the ideal gas constant $(8.3145 \mathrm{~J} / \mathrm{mol} \cdot \mathrm{K}), \quad T$ is the absolute temperature $(\mathrm{K}), K$ is a constant related to the energy of sorption and $C_{m}$ is the sorption capacity of adsorbent per unit weight $(\mathrm{mol} / \mathrm{kg})$.

The linear form of the equation above may be obtained by rearranging it to give:

$$
\ln [C]_{S}=\ln C_{m}-K \varepsilon^{2}
$$

If $\ln [C]_{S}$ is plotted against $\varepsilon^{2}, K$ and $\ln C_{m}$ will be obtained from the slope and the intercept, respectively. The value of $K(\mathrm{~mol} / \mathrm{kJ})^{2}$ is related to the adsorption mean free energy, $E(\mathrm{~kJ} / \mathrm{mol})$, defined as the free energy change required to transfer one mole of ions from infinity in solution to the solid surface. ${ }^{11}$ The relation is given as:

$$
E=(-2 K)^{-0.5}
$$

The D-R isotherm parameters $K, C_{m}$ and $E$ are given in Table 3. Based on $C_{m}$ values, the sorption capacity of chlorite-illite is larger than that of kaolinite. The magnitudes of the mean free energy of sorption, E, are in the range corresponding to ion-exchange type of adsorption. ${ }^{12}$

Table 2. Freundlich constants, $n$ and $k$, obtained from the least-square fits to the sorption data of $\mathrm{Ba}^{2+}$ on kaolinite and chlorite-illite

\begin{tabular}{ccccc}
\hline Temperature, K & \multicolumn{2}{c}{ Kaolinite } & \multicolumn{2}{c}{ Chlorite-illite } \\
& $n$ & $k$ & $n$ & $k$ \\
\hline 303 & 0.73 & 7.0 & 0.78 & 36.4 \\
313 & 0.75 & 8.9 & 0.78 & 34.6 \\
323 & 0.73 & 6.5 & 0.77 & 36.4 \\
333 & 0.73 & 6.3 & 0.80 & 40.2 \\
\hline
\end{tabular}

The linear correlation coefficients were all larger than 0.998 . 
Table 3. The D-R constants, $K(\text { in } \mathrm{mol} / \mathrm{kJ})^{2}$ and $C_{m}$ (in $\mathrm{mol} / \mathrm{kg}$ ) obtained from the least square fits to the sorption data of $\mathrm{Ba}^{2+}$ on kaolinite and chlorite-illite and the values of mean free energy, $E$ (in kJ/mol) values obtained from $K$ values

\begin{tabular}{ccccccc}
\hline Temperature, $\mathrm{K}$ & \multicolumn{3}{c}{ Kaolinite } & \multicolumn{3}{c}{ Chlorite-illite } \\
& $K$ & $C_{m}$ & $E$ & $K$ & $C_{m}$ & \multicolumn{2}{c}{. } \\
\hline 303 & 0.0052 & 17.0 & 9.8 & 0.0050 & 45.8 & 10.0 \\
313 & 0.0050 & 17.9 & 10.0 & 0.0047 & 44.3 & 10.3 \\
323 & 0.0045 & 14.9 & 10.5 & 0.0046 & 49.4 & 10.5 \\
333 & 0.0043 & 14.4 & 10.8 & 0.0043 & 48.9 & 10.4 \\
\hline
\end{tabular}

The linear correlation coefficients were all larger than 0.997.

Table 4. The enthalpy change, $\Delta H^{\circ}$ (in $\mathrm{kJ} / \mathrm{mol}$ ), the entropy change, $\Delta S^{\circ}$ (in $\mathrm{kJ} / \mathrm{mol} \cdot \mathrm{K}$ ) and the values of Gibbs free energy change, $\Delta G^{\circ}$ (in $\mathrm{kJ} / \mathrm{mol}$ ) of sorption obtained from the data of $\mathrm{Ba}^{2+}$ sorption on kaolinite and chlorite-illite

\begin{tabular}{|c|c|c|c|c|c|c|}
\hline & \multirow{2}{*}{$\begin{array}{c}\Delta H^{\circ} \pm \text { S.D. } \\
\mathrm{kJ} / \mathrm{mol}\end{array}$} & \multirow{2}{*}{$\begin{array}{c}\Delta S^{\circ} \pm \mathrm{S} . \mathrm{D} . \\
\mathrm{kJ} / \mathrm{mol} \cdot \mathrm{K}\end{array}$} & \multicolumn{4}{|c|}{$\Delta G^{\circ} \pm$ S.D., $\mathrm{kJ} / \mathrm{mol}$} \\
\hline & & & 303 & 313 & 323 & 333 \\
\hline Kaolinite & $-7 \pm 2$ & $0.021 \pm 0.005$ & $-13 \pm 2$ & $-14 \pm 2$ & $-15 \pm 2$ & $-15 \pm 2$ \\
\hline Chlorite-illite & $-5 \pm 3$ & $0.039 \pm 0.003$ & $-17 \pm 3$ & $-17 \pm 3$ & $-18 \pm 3$ & $-18 \pm 3$ \\
\hline
\end{tabular}

S.D.: Standard deviation.
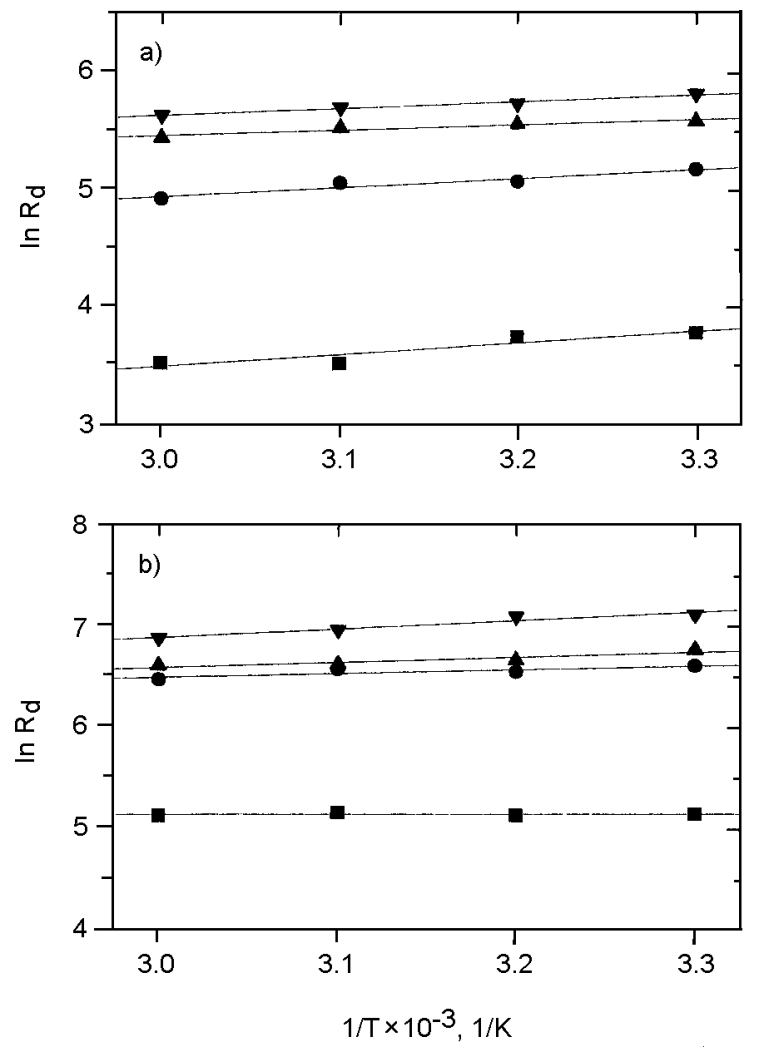

Fig. 4. The $\ln R_{d}$ versus $1 / T$ plots in the sorption of $\mathrm{Ba}^{2+}$ on, kaolinite (a), chlorite-illite (b) at different initial concentrations:

- $5.0 \cdot 10^{-4} \mathrm{~mol} / \mathrm{l} ; \bullet 5.0 \cdot 10^{-5} \mathrm{~mol} / \mathrm{l} ; \boldsymbol{\Delta} 5.0^{\cdot} 10^{-6} \mathrm{~mol} / \mathrm{l} ; \boldsymbol{\nabla} 5.0 \cdot 10^{-7} \mathrm{~mol} / 1$

\section{Thermodynamic results}

The enthalpy change, $\Delta H^{\circ}$, and the entropy change, $\Delta S^{\circ}$, of $\mathrm{Ba}^{2+}$ sorption on the clays were obtained by fitting the experimental data to the relation:

$$
\ln R_{d}=\frac{\Delta S^{\circ}}{R}-\frac{\Delta H^{\circ}}{R T}
$$

By plotting $\ln R_{d}$ versus $1 / T$, it is possible to determine the value of $\Delta H^{\circ}$ of sorption from the slope and $\Delta S^{\circ}$ of sorption from the intercept of the linear fits as given in Fig. 4.

The values of $\Delta H^{\circ}$ and $\Delta S^{\circ}$ reported in this work were calculated depending on the assumption that $R_{d}$ is an equilibrium constant. Actually $R_{d}$ is an empirical constant that corresponds to a particular initial concentration, and as such changes in $R_{d}$ at different initial concentrations lead to changes in the corresponding $\Delta H^{\circ}$ and $\Delta S^{\circ}$ values. In order to obtain values of $\Delta H^{\circ}$ and $\Delta S^{\circ}$ that are representative over the entire concentration ranges, averaged $\Delta H^{\circ}$ and $\Delta S^{\circ}$ of different sorption cases were calculated. Based on this, the $\Delta H^{\circ}$, and $\Delta S^{\circ}$ values obtained for $\mathrm{Ba}^{2+}$ sorption on both clays are given in Table 4 . The negative $\Delta H^{\circ}$ values indicate an exothermic sorption of $\mathrm{Ba}^{2+}$ on both clays. Positive $\Delta S^{\circ}$ values are usually associated with a spontaneous process where the system shows an endothermic behavior or even a weak exothermic behavior. As the exothermic behavior becomes more pronounced negative $\Delta S^{\circ}$ values are obtained. In the literature, it is reported that the positive values of $\Delta S^{\circ}$ resulting from sorption of divalent cations $\left(\mathrm{Ba}^{2+}\right.$ in this case) on solid surfaces might suggest that ions displaced from the solid surface are greater in number than the sorbed $\mathrm{Ba}^{2+}$ ions, which means that two monovalent ions may be exchanged for a single $\mathrm{Ba}^{2+}$ ion ${ }^{13}$.

Gibbs free energy of sorption, $\Delta G^{\circ}$, were calculated using the equation:

$$
\Delta G^{\circ}=\Delta H^{\circ}-T \Delta S^{\circ}
$$


$\Delta G^{\circ}$ values at various temperatures are given in Table 4. The negative values indicate that $\mathrm{Ba}^{2+}$ sorption is spontaneous in all cases.

The XRD diagrams of the clay samples before and after $\mathrm{Ba}^{2+}$ sorption indicate that whereas some intensity reductions in the primary chlorite and illite features were observed, no significant changes in the kaolinite features have accompanied the sorption process. Further XRD studies are required to reveal the plausible structural changes accompanying $\mathrm{Ba}^{2+}$ sorption on the chloriteillite clay.

Compared with $\mathrm{Cs}^{+}$sorption on clays, which was investigated in an earlier study, ${ }^{14} \mathrm{Ba}^{2+}$ sorption shows a weaker exothermic behavior and hence temperature variations seem to affect sorbed $\mathrm{Ba}^{2+}$ ions to a lesser extent.

If the sorption behavior of $\mathrm{Ba}^{2+}$ on kaolinite and chlorite illite is compared with that on bentonite investigated for the same concentration and temperature ranges, ${ }^{15}$ it can be concluded that the exothermic behavior is more pronounced for bentonite, thus indicating a more stable sorption. Moreover, bentonite showed a larger sorption capacity towards $\mathrm{Ba}^{2+}$ ions with the deviation of sorption from linearity being smaller than in the cases of kaolinite and chlorite-illite. This shows that the sorption sites of bentonite are more 'homogeneous' in terms of the sorption energy.

\section{References}

1. K. H. LIESER, Radiochim. Acta, 70/71 (1995) 355.

2. C. Eylem, H. N. ERTEN, H. GoKTURK, J. Environ. Radioact., 11 (1990) 183.

3. H. N. ERTEN, Z. GoKmenogLu, J. Radioanal. Nucl. Chem., 182 (1994) 375.

4. T. Shahwan, S. Suzer, H. N. Erten, Appl. Radiation Isotopes, 49 (1998) 915.

5. A. Grutter, H. R. von Gunten, E. Rossler, Radiochim. Acta, 58 (1992) 259.

6. P. C. Zhang, P. V. Brady, S. E. Arthur, W. Q. Zhou, D. Sawyer, D. A. Hesterberg, Coll. Surf. A. Physicochem. Eng. Aspects, 107 (1996) 89.

7. H. Catalette, J. Dumoceau, P. Ollar, J. Contam. Hydrol., 35 (1998) 151.

8. T. Shahwan, H. N. ERten, J. Radioanal. Nucl. Chem., 254 (2002) 563.

9. R. Kleven, J. Alstad, J. Petrol. Sci. Eng., 15 (1996) 181.

10. J. Pichtel, K. Kuroiwa, H. T. SAWYerR, Environ. Pollut., 110 (2000) 171.

11. S. AKsoyoglu, J. Radioanal. Nucl. Chem., 134 (1989) 393.

12. F. HelferRich, Ion Exchange, Mc Graw Hill, New York, 1964.

13. S. A. Khan, R. Reman, M. A. Khan, J. Radioanal. Nucl. Chem., 190 (1995) 81.

14. T. Shahwan, H. N. ERten, J. Radioanal. Nucl. Chem., 253 (2002) 115.

15. T. Shahwan, H. N. ERTen, Radiochim. Acta, 89 (2001) 799. 